\title{
Clinical experience with transvenous atrial pacing
}

\author{
J. S. GEDDES, S. W. WEBB, AND I. P. CLEMENTS \\ From the Cardiac Department, Royal Victoria Hospital, Belfast, Northern Ireland
}

SUMMARY Twelve patients were paced with a transvenous J-shaped bipolar electrode positioned in the right atrial appendage. All had chronic sinoatrial dysfunction and 5 had paroxysmal atrial arrhythmia: 2 had recent myocardial infarction, 1 angina decubitus, and 1 ventricular pre-excitation. Atrioventricular sequential pacing was employed in this last patient and this mode of pacing was substituted for atrial pacing in one other. The remaining 10 patients were paced from the atrium only.

Electrode displacement occurred in 2 patients and 2 others had a rise in pacing threshold. After repositioning the electrode or substituting a more powerful pacemaker, sustained atrial capture was achieved in 3 of these 4 . Sensing of spontaneous $P$ waves was present constantly in 4 and variably in 3 of 9 patients. Symptomatic improvement was obtained in 10 patients.

A bipolar pacemaker with a variable output voltage and a relatively high demand sensitivity is optimal for atrial pacing. Measurements of intra-atrial voltage with various electrode configurations in 7 patients suggest that atrial sensing may more often be achieved when the reference electrode is situated in the upper part of the right atrium than when it is close to the electrode tip in the atrial appendage.

Atrial pacing may be superior to ventricular pacing in the management of patients with chronic sinus node dysfunction but without advanced atrioventricular block. The cardiac output is higher and the pacing rate haemodynamically less important with a normal atrioventricular sequence (Sowton et al., 1973). Prevention of atrial slowing may suppress the development of atrial arrhythmia, which carries a significant risk of embolism (Rubenstein et al., 1972; Aroesty et al., 1974).

Continuous atrial or sequential atrioventricular stimulation may be effective in the control of refractory arrhythmias (Dreifus et al., 1975). Intermittent stimulation is employed for the removal of recurrent atrial tachycardia resistant to drugs, and the pacing system is activated externally when required (Williams and Davison, 1974; Kahn et al., 1976).

Successful transvenous atrial pacing has been reported, using J-shaped electrodes positioned in the right atrial appendage (Smyth et al., 1971; Zucker et al., 1973) or electrodes of a more conventional shape, either fixed to the atrial wall (Moore and Bower, 1975) or advanced into the coronary sinus (Moss et al., 1974). Udall (1974) introduced a T-shaped electrode transseptally into the left atrium. Evidence is, however, lacking that

Received for publication 18 May 1977 any transvenous technique has yet gained wide acceptance.

Fields et al. (1973) reported a low incidence of complications among a series of 48 patients in whom a 'J' electrode was used as part of a sequential atrioventricular pacing system. This report concerns 12 consecutive patients with sinus node dysfunction in whom atrial pacing was attempted with this electrode. ${ }^{1}$ Where possible the atria alone were paced and pacemakers intended primarily for ventricular pacing were implanted.

\section{Patients and methods}

Clinical details of the 12 patients are presented in the Table. Seven were men and the ages of the 12 patients ranged from 46 to 79 years. All had chronic symptomatic sinus bradycardia. Five had major or minor syncopal attacks and 5 , including 2 with recent myocardial infarction had symptoms or signs of cardiac decompensation without asystole. One patient (case 10) had inoperable coronary artery disease and it was thought that bradycardia was contributing to his angina; bradycardia also precluded the use of $\beta$-sympathetic blocking drugs. The twelfth patient (case 8) had paroxysmal atrial tachycardia and fibrillation in association with an

${ }^{1}$ Manufactured by the American Optical Corporation, now obtainable from Medtronic Inc., Minneapolis, Minnesota, USA. 
Table Clinical and technical data and results

\begin{tabular}{|c|c|c|c|c|}
\hline $\begin{array}{l}\text { Case } \\
\text { No. }\end{array}$ & Sex & $\begin{array}{l}\text { Age } \\
(y)\end{array}$ & $\begin{array}{l}\text { Diagnosis and } \\
\text { indications }\end{array}$ & $\begin{array}{l}\text { Atrioventricular } \\
\text { conduction }\end{array}$ \\
\hline $\begin{array}{l}1 \\
2 \\
3\end{array}$ & $\begin{array}{l}\mathrm{M} \\
\mathrm{M} \\
\mathrm{F}\end{array}$ & $\begin{array}{l}55 \\
73 \\
79\end{array}$ & $\begin{array}{l}\text { Low output } \\
\text { Brady/tachy ; asystole } \\
\text { Dyspnoea; asystole }\end{array}$ & $\begin{array}{l}\text { Satisfactory } \\
\text { Satisfactory } \\
\text { Satisfactory }\end{array}$ \\
\hline 4 & F & 64 & $\begin{array}{l}\text { Myocardial infarction; } \\
\text { congestive failure }\end{array}$ & Satisfactory \\
\hline 5 & $\mathbf{M}$ & 46 & Brady/tachy; asystole & Satisfactory \\
\hline & $\mathbf{M}$ & 67 & $\begin{array}{l}\text { Brady/tachy; } \\
\text { dyspnoea }\end{array}$ & Satisfactory \\
\hline 7 & $\mathbf{F}$ & 52 & $\begin{array}{l}\text { Myocardial infarction; } \\
\text { congestive failure }\end{array}$ & Digitalis sensitive \\
\hline 8 & $\mathbf{F}$ & 62 & $\begin{array}{l}\text { Pre-excitation } \\
\text { brady/tachy }\end{array}$ & $\begin{array}{l}\text { Grade } 1 \mathrm{AV} \\
\text { nodal block }\end{array}$ \\
\hline 9 & $\mathbf{M}$ & 58 & Asystole & Satisfactory \\
\hline 10 & $\mathbf{M}$ & 63 & Angina decubitus & Satisfactory \\
\hline 11 & $\mathbf{F}$ & 67 & Congestive failure & Digitalis sensitive \\
\hline 12 & $\mathbf{M}$ & 58 & Brady/tachy; asystole & Satisfactory \\
\hline
\end{tabular}

Procedure Pacemaker
Threshold/pulse Intra-atrial voltage duration (V/ms) Confi
used

$\begin{array}{ll}\text { Medtronic } 5942 & 1 \cdot 85 / 1 \cdot 0 \\ \text { Medtronic } 5942 & 1 \cdot 60 / 1 \cdot 0\end{array}$

$\begin{array}{ll}\text { Medtronic } 5942 & 1 \cdot 60 / 1 \cdot 0 \\ \text { Medtronic } 5943 & 0 \cdot 80 / 1 \cdot 0\end{array}$

$3.5^{\star} \begin{array}{ll}3.5 \\ 6.0 \\ \end{array}$

$\begin{array}{ll}\text { Medtronic } 5942 & 1 \cdot 00 / 1 \cdot 0 \\ \text { Devices 3821 } & 1.00 / 1 \cdot 0 \\ \text { Medtronic 5950 } & 1.25 / 0.5\end{array}$

Medtronic 5950

$0 \cdot 70 / 0 \cdot 5$

Medtronic $5950 \quad 1 \cdot 40 / 0 \cdot 5$

American pacemaker 3.80/1.0 28145 'bifocal'

American pacemaker 0.95/1.0 28145 'bifocal'

Miedtronic 5944‡

Medtronic 5944

Medtronic 5942

Medtronic 5950

Medtronic 5990

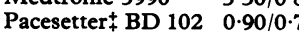

Pacesetter $\ddagger$ BD $102 \quad 0.95 / 0 \cdot 7$
$1 \cdot 00 / 0 \cdot 5$

$1 \cdot 30 / 0 \cdot 5$

$1 \cdot 10 / 1 \cdot 0$

*Unipolar.

†Anode in upper right atrium.

†Inhibit sensitivity approx $1 \mathrm{mV}$.

accessory pathway and had grade 1 atrioventricular nodal block. She had been managed with a combination of ventricular pacing and drugs; breathlessness and fatigue necessitated the restoration of a normal atrioventricular sequence. Four of the other 11 patients had had one or more documented episodes of atrial flutter or fibrillation.

Atrial pacing alone was attempted in 11 of the 12 patients. Atrioventricular conduction was tested by rapid atrial pacing before pacemaker implantation. Grade 2 block appeared at rates in excess of 110 per minute in all but 2 of these 11 patients. When digitalis was withdrawn or the dose reduced the rate producing block increased conspicuously in both. An atrioventricular sequential pacemaker was later required in one of these. A sequential pacemaker was implanted initially in the patient with preexcitation. Electrophysiological investigation had indicated that induction of atrial tachycardia by premature atrial stimulation was consistently prevented by introduction of a premature ventricular stimulus up to $310 \mathrm{~ms}$ after the atrial test stimulus.

Bipolar pacemakers were implanted in 9 of the 11 patients paced from the right atrium. Two of these 9 received pacemakers with a relatively high demand sensitivity of approximately $1 \mathrm{mV}$. Unipolar pacemakers were used on 2 occasions. The 2 atrioventricular sequential, ventricle-inhibited 'bifocal' pacemakers were implanted using a unipolar ventricular electrode, with an indifferent electrode near the pacemaker. The pacing rate ranged from 70 to 85 per minute.

The bipolar ' $\mathrm{J}$ ' electrode (American Optical Corporation model 283125) was implanted by the technique described by Zucker et al. (1973). Stylets straightened the electrode during venous catheterisation. When the terminal portion was in the right atrium the stylets were withdrawn, causing the electrode to take up its characteristic shape. The tip was positioned near the apex of the right atrial appendage and maintained in place by slight traction. The right cephalic vein was used in all but 4 patients in whom the left cephalic (3) or left external jugular vein (1) was catheterised. Fig. 1 illustrates the final electrode position. One patient (case 9) had an additional straight electrode positioned in the upper right atrium and this was used as the anode.

Pacing voltage thresholds were determined using a Devices stimulator, type B. Pulse duration was commensurate with that of the pacemaker to be 


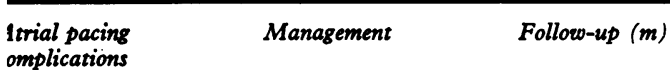

omplications

\begin{tabular}{|c|c|c|}
\hline$\overline{-}$ & & $\begin{array}{l}\text { Well ( } 35) \\
\text { Well; paroxysmal AF (25) } \\
\text { SVT converted by fixed } \\
\text { rate pacing; died } \\
\text { cerebrovascular } \\
\text { accident ( } 2) \\
\text { Well (19) }\end{array}$ \\
\hline $\begin{array}{l}\text { jlectrode displacement } \\
\text { Threshold rise: } \\
\text { periodic vent. pacing }\end{array}$ & $\begin{array}{l}\text { Repositioning from } \\
\text { different vein; } \\
\text { Ventricular pacing } \\
\text { electrode substituted }\end{array}$ & $\begin{array}{l}\text { Ventricular electrode } \\
\text { perforated (5); now } \\
\text { well with atrial pacing } \\
\text { from electrode in } \\
\text { coronary sinus (13) }\end{array}$ \\
\hline - & & $\begin{array}{l}\text { Initial improvement; AF } \\
\text { and LV failure (12); } \\
\text { DC conversion; died } \\
\text { (14) }\end{array}$ \\
\hline Threshold rise & $\begin{array}{l}\text { Atrioventricular } \\
\text { sequential pacemaker } \\
\text { substituted }\end{array}$ & $\begin{array}{l}\text { Persistent congestive } \\
\text { failure; died suddenly } \\
\text { (2) } \\
\text { Well; no tachycardia (12) }\end{array}$ \\
\hline$\overline{-}$ & & $\begin{array}{l}\text { Well (10) } \\
\text { Angina improved (9) }\end{array}$ \\
\hline $\begin{array}{l}\text { Threshold rise } \\
\text { Recurrent threshold rise }\end{array}$ & $\begin{array}{l}\text { Repositioning } \\
\text { High output pacemaker } \\
\text { substituted }\end{array}$ & Well (7) \\
\hline Jlectrode displacement & Repositioning & $\begin{array}{l}\text { Well (5); DC conversion } \\
\text { for single recurrence } \\
\text { of AF }\end{array}$ \\
\hline
\end{tabular}

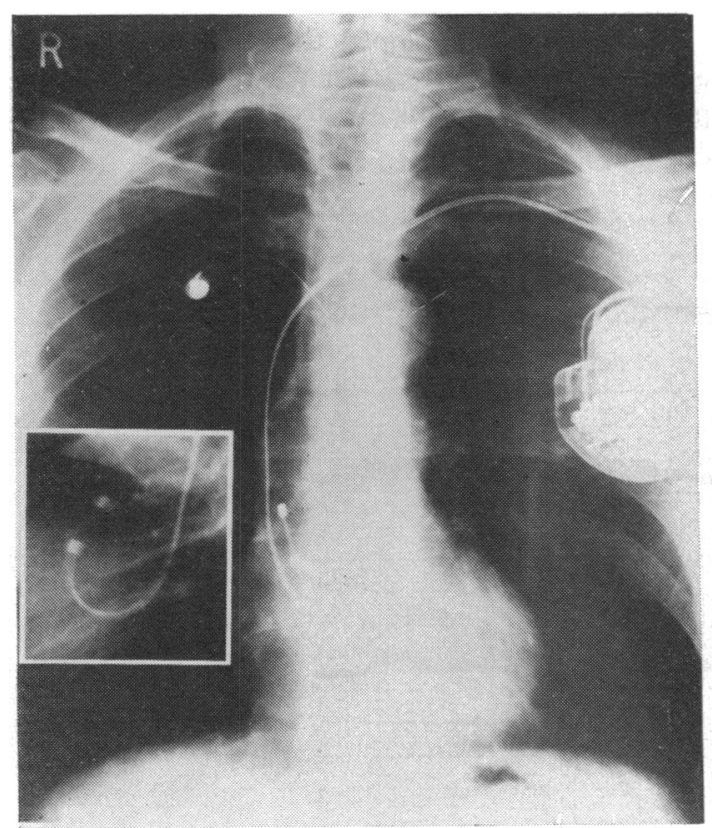

Fig. 1 Posteroanterior chest radiograph showing the position of the atrial electrode. Inset : lateral radiograph showing anterior position of the tip. implanted. Bipolar intra-atrial electrograms were recorded using a standard electrocardiograph. The atrial complexes were measured from peak to trough. Seven patients had measurements of the $P$ wave voltage recorded between the tip of the permanent electrode and an exploring electrode positioned at various sites within the right atrium and superior vena cava in addition to the standard record between tip and collar electrodes.

Haemodynamic investigation was performed in 1 patient (case 1) during atrial and ventricular pacing at a rate of $75 / \mathrm{min}$ both at rest and during the last 30 seconds of 90 -second periods of supine leg exercise. Multiple measurements of cardiac output were made by injection of $4.5 \mathrm{mg}$ indocyanine green dye into the right atrium, with sampling from the descending aorta. A minimum of 3 minutes elapsed between a change in pacing mode and the next measurement of output.

\section{Results}

Atrial capture was maintained in 8 of the 12 patients and atrial sensing was present constantly in 4 and variably in 3 of the 9 patients in whom attempted atrial demand pacing was continued (Table). Sensing was constant in both of the patients who received pacemakers with a demand sensitivity of $1 \mathrm{mV}$.

Electrode displacement occurred in 2 patients (on the second and tenth days) and recurred in 1 of them after the electrode was removed from the left cephalic vein and was repositioned from the right cephalic. The shape of this patient's right atrial appendage may have been unusual. Eventually, stable atrial pacing was achieved with a straight bipolar electrode inserted into the coronary sinus after ventricular pacing had been complicated by perforation of the ventricle.

Two patients had a rise in stimulation threshold. Repositioning was performed on the sixth day in 1 of these. A recurrent rise in threshold caused failure of capture, and the pacemaker was replaced with a high output unit, with which satisfactory pacing has been maintained. The other patient presented with failure of capture at 8 weeks. Since grade 2 atrioventricular block had appeared at a pacing rate of 85 per minute while this patient had been receiving digitalis, and since digitalisation was required for control of persistent congestive cardiac failure, the pacemaker was replaced with a 'bifocal' unit. The higher voltage of this pacemaker achieved satisfactory atrial capture.

The mean bipolar intra-atrial $P$ wave voltage was $3.3 \mathrm{mV}$ (range 0.2 to 6.0 ). The voltage recorded was 
critically dependant on the position of the positive 'collar' electrode and fell by 64 per cent in 1 patient when the collar was moved by slight rotation of the proximal end of the electrode.

When the bipolar electrogram was recorded between the tip of the electrode in the right atrial

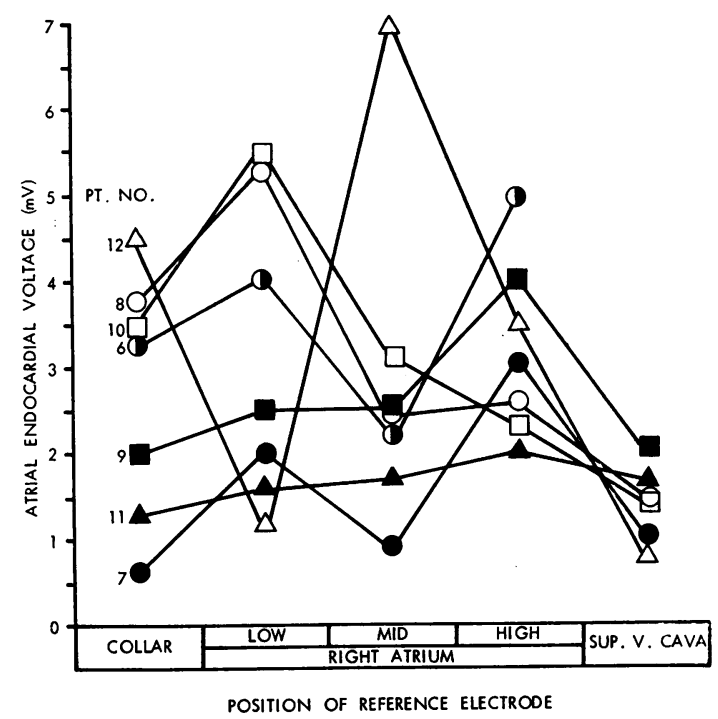

Fig. 2 Effect of position of the reference electrode on magnitude of atrial signal in 7 patients. The voltages were recorded immediately after insertion of the electrode and are not invariably identical with the final voltage presented in the Table. appendage and various other sites in 7 patients, distinct variation in the amplitude of the atrial signal was apparent (Fig. 2 and 3). The upper right atrium was the only position of the reference electrode where the recorded voltage was invariably 2 millivolts or greater. Though the mean voltage was only slightly higher in this position $(3.2 \mathrm{mV})$ than with the standard bipolar configuration in these 7 patients $(2.7 \mathrm{mV})$, the voltage was appreciably higher in 4 patients of whom 3 had the lowest recorded standard bipolar voltages (mean difference $1.6 \mathrm{mV}$ ).

The patient with ventricular pre-excitation has had no further attacks of atrial tachycardia or fibrillation. One patient (case 12) required DC conversion for a recurrence of atrial fibrillation during the postoperative period. Another (case 2) has continued to have occasional self-terminating episodes of atrial fibrillation. A further patient (case 3), who did not have prior documented tachyarrhythmia, developed paroxysmal supraventricular tachycardia during the postoperative period, and activation of the pacemaker with a magnet terminated the attacks. Frequent ventricular ectopic beats appeared in a patient (case 6) who was paced at a rate of 85 per minute. The ectopics were controlled with mexiletine. This patient later developed recurrent atrial fibrillation in association with an episode of left ventricular failure. Atrial pacing was restored after DC shock.

Two patients developed their first documented episode of atrial flutter or fibrillation during manipulation of the pacing electrode. Removal of the

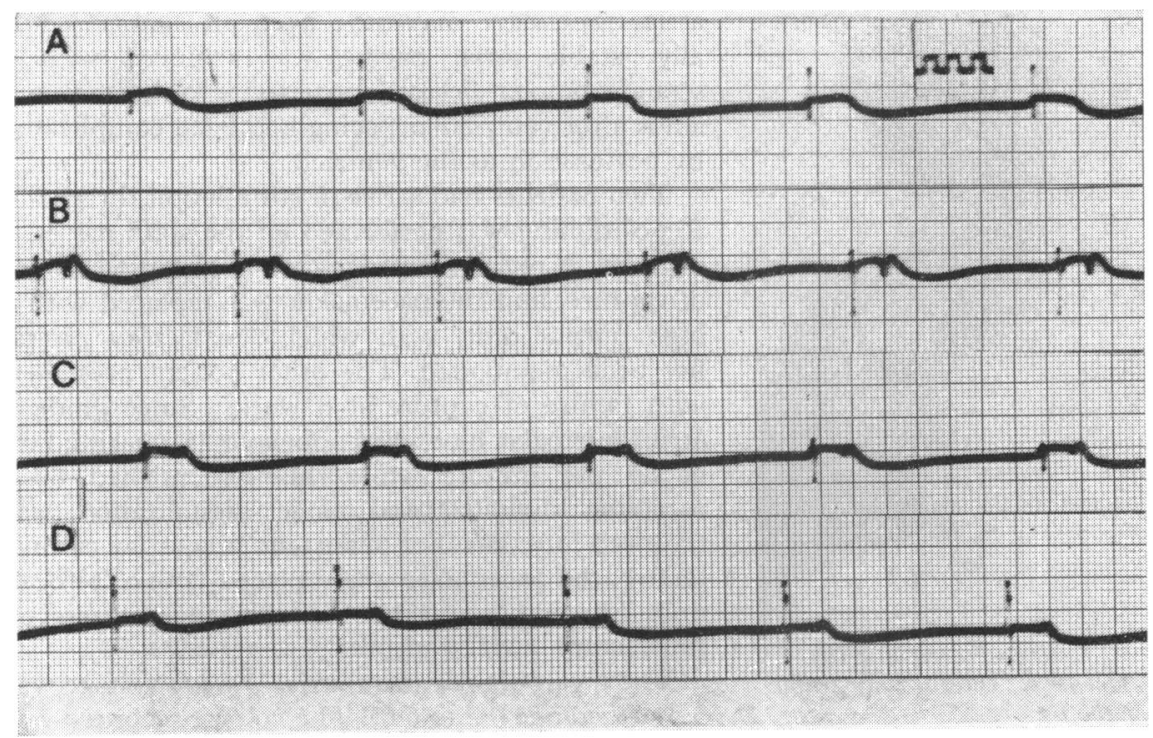

Fig. 3 Case 6. Bipolar endocardial electrograms with reference electrode: (A) Collar of bipolar 'J' electrode; (B) lower right atrium; (C) mid right atrium; (D) high right atrium. Calibration signal $1 \mathrm{mV}$. 
arrhythmia by DC shock or rapid atrial pacing was required during the implantation procedure in these and in 2 others whose arrhythmia was spontaneous.

The patient who had measurements of cardiac output had complained of extreme fatigue when first seen. Resting output increased by 62 per cent and output during exercise by 50 per cent during atrial pacing, but ventricular pacing had no effect either at rest or during exercise.

Pacemaker malfunction was apparent 3 months after implantation in 1 of the 2 patients who received sequential pacemakers, with a reduction in pacing rate from 80 to 71 per minute. Because the rate in the fixed rate mode was unchanged the pacemaker has not been replaced.

Three patients have died. A 79-year-old woman died of a cerebrovascular accident 2 months after pacemaker implantation. An electrocardiogram recorded shortly before her death showed stable atrial pacing. Another patient, who received a sequential pacemaker after failure of atrial capture, died suddenly 2 months after the last procedure. She had chronic congestive cardiac failure which was not appreciably improved by pacing; necropsy was not performed. The third patient died suddenly in another hospital where he was being treated for deep venous thrombosis and pulmonary embolism; death probably resulted from a further embolus. His initial response to pacing had been good but cardiac decompensation had reappeared at 12 months.

The surviving patients had significant or total relief of symptoms. Fatigue was immediately abolished in case 1, whose cardiac output had increased during atrial pacing. Congestive failure was controlled in 2 patients. No patient had syncope. The mean follow-up period for the 8 survivors still paced from the right atrial appendage was 15 months.

\section{Discussion}

It is apparent that permanent atrial pacing can usually be achieved with the J-shaped transvenous electrode employed in this series. No further procedures have been required in 8 of the 12 patients and stable atrial pacing has been achieved in 3 others after repositioning of the electrode or substitution of a more powerful pacemaker. In only 1 patient was the right atrial pacing site abandoned, because of recurrent electrode displacement. Smyth et al. (1976) have recently suggested that greater stability may be achieved if flexible projections, or 'tines', are attached to the terminal few centimetres of a ' $\mathrm{J}$ ' electrode.

A relatively large vein is required for insertion of the wide electrode (maximum dimensions $4.5 \times$ $3 \mathrm{~mm}$ ). Otherwise the technique is not appreciably more difficult than that for implantation of a ventricular pacemaker. Placement of the electrode tip in the right atrial appendage is usually possible without lateral fluoroscopy.

Pulse generators with low energy outputs intended for ventricular pacing are usually sufficiently powerful for atrial pacing. Nevertheless, the significant incidence (2 out of 12) of rise in threshold beyond the output of the generator in this series suggests that units with a higher potential output are preferable.

The atrial endocardial voltage measured with a standard electrocardiograph is lower than that usually recorded from the ventricle. The bipolar voltages (mean $3.3 \pm S E 0.4 \mathrm{mV}$ ) recorded from our patients were insignificantly higher than the unipolar voltages obtained in 2 series, comprising 28 patients, by Smyth et al. (1971 and 1976) using a different type of ' $\mathrm{J}$ ' electrode (mean $2.8 \pm \mathrm{SE}$ $0.3 \mathrm{mV}$ ).

Among the 7 patients who had measurements of endocardial voltage from various lead configurations, the variation in the amplitude of the $P$ wave recorded with the indifferent electrode situated in the upper right atrium was less than when records were made with the standard bipolar configuration, both among the same 7 patients and the remaining 5 in whom only the latter measurement was made. The number of patients is too small for statistical evaluation. Nevertheless it is logical to speculate that, where the voltage recorded from the right atrial appendage is low, it may be supplemented by the signal resulting from activation of another atrial site. The likelihood of cancellation of the signals detected at the active and indifferent electrodes may be reduced when the indifferent electrode is in another part of the atrium. A close approximation of the reference electrode to the atrial wall is most likely if the electrode is near the relatively narrow junction of the right atrium and superior vena cava.

In 1 patient (case 9) a unipolar electrode was positioned in the upper right atrium and connected to the positive pole of the pacemaker. The $P$ wave amplitude of $4 \mathrm{mV}$ achieved in this way permitted satisfactory sensing by the pacemaker. The data presented suggest that manufacture of the ' $\mathrm{J}$ ' electrode with its positive collar situated a few centimetres proximal to the apex of the loop, bringing it to lie in the upper part of the right atrium following insertion, may result in improved sensing in a significant proportion of patients. An added advantage of this configuration would be that the terminal portion of the catheter, comprising the loop, would contain only one electrode wire. 
The additional insulation necessary to maintain the loop might thus be made less bulky, facilitating insertion in the vein.

Whichever electrode configuration is employed, the atrial voltage will often be insufficient to inhibit standard demand pacemakers, and a pacemaker with a sensitivity of approximately $1 \mathrm{mV}$ will be required.

The pulse generator best suited for atrial pacing with the ' $\mathrm{J}$ ' electrode will have a variable output voltage. Reoperation might have been avoided in 2 of our patients if pacemakers with higher outputs had been implanted. The suggested demand sensitivity of $1 \mathrm{mV}$ is similar to that recommended or used by others (Smyth et al., 1971; Furman, 1973). Since it is apparent that the atrial signal is of relatively high frequency, the sensitivity should not be attenuated in the higher frequency range, as is the case with the Medtronic model 5950 pacemaker. Since the $Q R S$ voltage is small, a prolonged refractory period is unnecessary, in contrast to the situation when pacing is attempted from the coronary sinus (Moss et al., 1974). A bipolar lead configuration is required because the high sensitivity will otherwise increase the vulnerability to inappropriate inhibition by skeletal muscle potentials.

A pacemaker with the above specification will also find some application for ventricular pacing, where there has been an unusually large increase in pacing threshold or where the endocardial voltage is low or of inappropriate frequency content for the sensing circuitry incorporated in some ventricular pacemakers (Sutton et al., 1975).

No patient has developed permanent atrial fibrillation after pacemaker implantation. The value of atrial pacing and the optimal pacing rate for the prophylaxis of atrial fibrillation in the presence of sinus node dysfunction have yet to be determined. Atrial arrhythmia has been completely suppressed in the unusual patient with grade 1 atrioventricular nodal block and pre-excitation using the 'bifocal' pacemaker, with an atrioventricular interval of $175 \mathrm{~ms}$.

The finding of an improved resting cardiac output only during atrial pacing in 1 of our patients is in accord with the report by Sowton et al. (1973). These authors were unable to show a correspondingly improved exercise tolerance during pacing with a normal atrioventricular sequence in comparison with ventricular pacing. Our patient's symptom of fatigue was removed dramatically by atrial pacing.

The possibility that, in the event of failure of demand function, a stimulus coinciding with the atrial vulnerable period will result in ventricular fibrillation is remote. An earlier patient, a 51-yearold man with sick sinus syndrome and paroxysmal atrial fibrillation, who had a unipolar ventricular pacing system, was found lying dead beside a trench that he had been digging 1 year after pacemaker implantation. The pacemaker was functioning normally. Severe coronary atheroma without total occlusion of any vessel was found at necropsy. It is possible that a rapid ventricular rate associated with atrial fibrillation and strenuous exercise, high sympathetic tone, and digitalis (which he had been taking) combined to lower the ventricular fibrillation threshold, while continuous sensing of skeletal muscle potentials during exercise resulted in fixed rate operation of the pacemaker. One of the asynchronous stimuli may have precipitated ventricular fibrillation. Fixed rate operation of a similar pacemaker (Medtronic model 5943) was

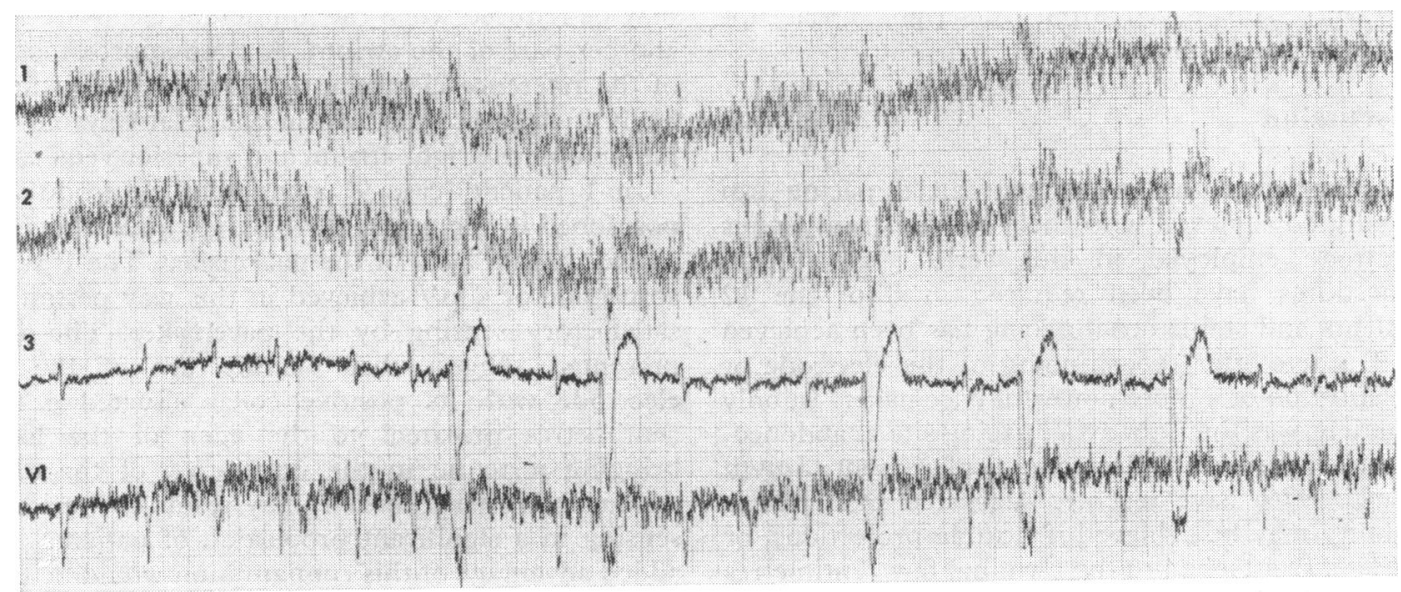

Fig. 4 Electrocardiogram of a patient showing asynchronous competitive ventricular pacing during contraction of pectoral muscles. 
subsequently shown in another patient with a ventricular electrode during contraction of the pectoral muscles (Fig. 4). Though sensing of skeletal myopotentials could not cause fixed rate operation if a bipolar ventricular electrode were used, sensing failure from other sources, such as inadequate ventricular endocardial voltage or an electronic fault in the pacemaker, is occasionally seen.

The routine use of atrioventricular sequential pacemakers has been recommended for the management of the sick sinus syndrome (Fields et al., 1973). Nevertheless, sequential pacemakers are approximately twice as expensive as pacemakers with a single output and because of their complexity a higher failure rate may be anticipated than with conventional pulse generators. One report has indicated a significant incidence of premature failure (Furman et al., 1973).

Although rapid atrial pacing indicated that atrioventricular conduction was impaired in 2 patients while they were taking digitalis, grade 2 atrioventricular block did not occur after pacemaker implantation. It seems justifiable to employ atrial pacing alone provided that one-to-one atrioventricular conduction without significant prolongation of the $P R$ interval is maintained during pacing at rates 15 to 20 beats faster than the rate of the pacemaker to be implanted. Later deterioration of atrioventricular conduction may be treated by substitution of a ventricular pacing electrode or of a sequential pacemaker. Subsequent insertion of a unipolar ventricular pacing electrode may readily be performed by direct puncture of the subclavian vein from the upper part of the pectoral pocket. The theoretical risk of sensing of the atrial stimulus by the unipolar ventricular electrode did not materialise in 2 patients with this electrode configuration.

In conclusion, transvenous atrial demand pacing with a ' $\mathrm{J}$ ' electrode is a practical proposition. Optimal results are likely if a bipolar electrode with its proximal pole located high in the right atrium is employed and if variable output pacemakers with a demand sensitivity of $1 \mathrm{mV}$ are implanted. For reasons of cost and reliability sequential atrioventricular pacing is best reserved for situations where atrioventricular conduction is more than mildly impaired or 'bifocal' pacing is required for suppression of tachyarrhythmias.

\section{Addendum}

Four additional patients have been paced with ' $\mathrm{J}$ ' electrodes since the preparation of this manuscript. Three have had an uncomplicated course. The fourth patient required electrode repositioning 24 hours after pacemaker implantation and is now pacing satisfactorily.

\section{References}

Aroesty, J. M., Cohen, S. I., and Morkin, E. (1974). Bradycardia-tachycardia syndrome: results in twenty-eight patients treated by combined pharmacologic therapy and pacemaker implantation. Chest, 66, 257-263.

Dreifus, L. S., Berkovits, B. V., Kimibiris, D., Moghadam, K., Haupt, G., Walinsky, P., Thomas, P., and Brockman, S. K. (1975). Use of atrial and bifocal cardiac pacemakers for treating resistant dysrhythmias. European fournal of Cardiology, 3, 257-266.

Fields, J., Berkovits, B. V., and Matloff, J. M. (1973). Surgical experience with temporary and permanent $\mathrm{A}-\mathrm{V}$ sequential demand pacing. Fournal of Thoracic and Cardiovascular Surgery, 66, 865-877.

Furman, S. (1973). Therapeutic uses of atrial pacing. American Heart fournal, 86, 835-840.

Furman, S., Reicher-Reiss, H., and Escher, D. J. W. (1973). Atrioventricular sequential pacing and pacemakers. Chest, 63, 783-789.

Kahn, A., Morris, J. J., and Citron, P. (1976). Patientinitiated rapid atrial pacing to manage supraventricular tachycardia. American fournal of Cardiology, 38, 200-204.

Moore, C. B., and Bower, P. J. (1975). The sick sinus syndrome: treatment by permanent transvenous atrial pacing (a new approach). Southern Medical fournal, 68, 580-583.

Moss, A. J., Rivers, R. J., Jr., and Kramer, D. H. (1974). Permanent pervenous atrial pacing from the coronary vein: long-term follow-up. Circulation, 49, 222-225.

Rubenstein, J. J., Schulman, C. L., Yurchak, P. M., and DeSanctis, R. W. (1972). Clinical spectrum of the sick sinus syndrome. Circulation, 46, 5-13.

Smyth, N. P. D., Citron, P., Keshishian, J. M., Garcia, J. M., and Kelly, L. C. (1976). Permanent pervenous atrial sensing and pacing with a new J-shaped lead. Fournal of Thoracic and Cardiovascular Surgery, 72, 565-570.

Smyth, N. P. D., Keshishian, J. M., Bacos, J. M., Massumi, R. A., Fletcher, R. D., and Boivin, M. R. (1971). Permanent pervenous atrial pacing. Fournal of Electrocardiology, 4, 299-306.

Sowton, E., Thorburn, C., and Roy, P. (1973). Haemodynamic changes during cardiac pacing. In Cardiac Pacing : Proceedings of 4th International Symposium, p. 24. Ed. by H. J. Th. Thalen. van Gorcum, Assen.

Sutton, R., Norman, J., and Briers, L. (1975). Sick sinus syndrome. British Medical fournal, 3, 367-368 (letter).

Udall, J. A. (1974). Permanent pervenous transseptal atrial pacing: canine experiments and a clinical case. American fournal of Cardiology, 33, 887-891.

Williams, D. O., and Davison, P. H. (1974). Long-tern treatment of refractory supraventricular tachycardia by patient-controlled inductive atrial pacing. British Heart Fournal, 36, 336-340.

Zucker, I. R., Parsonnet, V., and Gilbert, L. (1973). A method of permanent transvenous implantation of an atrial electrode. American Heart fournal, 85, 195-198.

Requests for reprints to J. S. Geddes, Cardiac Department, Royal Victoria Hospital, Belfast BT12 $6 \mathrm{BA}$, Northern Ireland. 